\title{
Danger of injudicious use of tui-na therapy in ankylosing spondylitis
}

\author{
Gen Zou ${ }^{1,2} \cdot$ Guyi Wang ${ }^{2} \cdot$ Jinxiu $\mathrm{Li}^{2} \cdot$ Guobao $\mathrm{Wu}^{2} \cdot \mathrm{Jia} \mathrm{Huang}^{2} \cdot$ Siyang Huang ${ }^{3}$
}

Received: 13 October 2016/Revised: 13 January 2017/ Accepted: 10 February 2017/Published online: 17 February 2017

(C) The Author(s) 2017. This article is published with open access at Springerlink.com

\begin{abstract}
Tui-na is a very important component of Chinese medicine. It is a well-respected treatment modality known to be helpful and safe for a wide range of conditions. It can be considered as a certain kind of massage which is performed at acupoints, meridians, and collaterals by pushing, finger twisting, grasping thumb waving pressing, patting, palm twisting, and other manipulation techniques. At present, it is extensively used for relieving pain and stiffness associated with ankylosing spondylitis in China, even though there is a lack of evidence to support its validation and feasibility. The patient in this case was treated by tuina massage at acute flare-up of ankylosing spondylitis and ended up with catastrophic results.
\end{abstract}

Keywords Ankylosing spondylitis - Cervical dislocation · Tui-na therapy

Jia Huang

huangjia10@csu.edu.cn

$\bowtie$ Siyang Huang sy_huang1996@163.com

1 Department of Gynaecology, Women's Hospital, Zhejiang University School of Medicine, Hangzhou,

Zhejiang Province, People's Republic of China

2 Department of Intensive Care Unit, The Second Xiangya Hospital, Central South University, Renmin Road 139, Changsha, Hunan Province, People's Republic of China

3 XiangXing College of Hunan University of Chinese Medicine, Changsha, Hunan Province, People's Republic of China

\section{Introduction}

Ankylosing spondylitis (AS) known as rheumatoid spondylitis has a characteristic of not only reduced but also increased bone formation which contributes to joint ankylosis and syndesmophyte formation, especially in advanced stages [1]. Osteoporosis is considered as a common feature of AS even in early period of the disease [2]. Tui-na is an important part of Traditional Chinese Medicine and is alternatively used in combination with acupuncture and other manipulation techniques to treat AS in China $[3,4]$. In this case, the patient with AS was injudiciously treated with tui-na therapy for neck pain and stiffness and end up with catastrophic results.

\section{Case report}

A 34-year-old male was admitted to our Emergency Department with quadriplegia (power 0 of 5) and labored breathing, whose radiographs showed fracture dislocation $\mathrm{C} 4-\mathrm{C} 5$ involving all three columns with distraction and angulation of the spine between $\mathrm{C} 4$ and C5 (Fig. 1). After history recording, we found that he was a known case of ankylosing spondylitis (AS), and had received long-term tui-na therapy to relieve chronic neck pain and stiffness. During the massage process $12 \mathrm{~h}$ before, he complained of a sudden severe pain in neck and then became tetraplegic. Therefore, he was quickly transported to our hospital for further treatment. However, due to the respiratory failure and cardiovascular dysfunction, which emerged sequentially and deteriorated rapidly, the patient died 7 days after admission. 

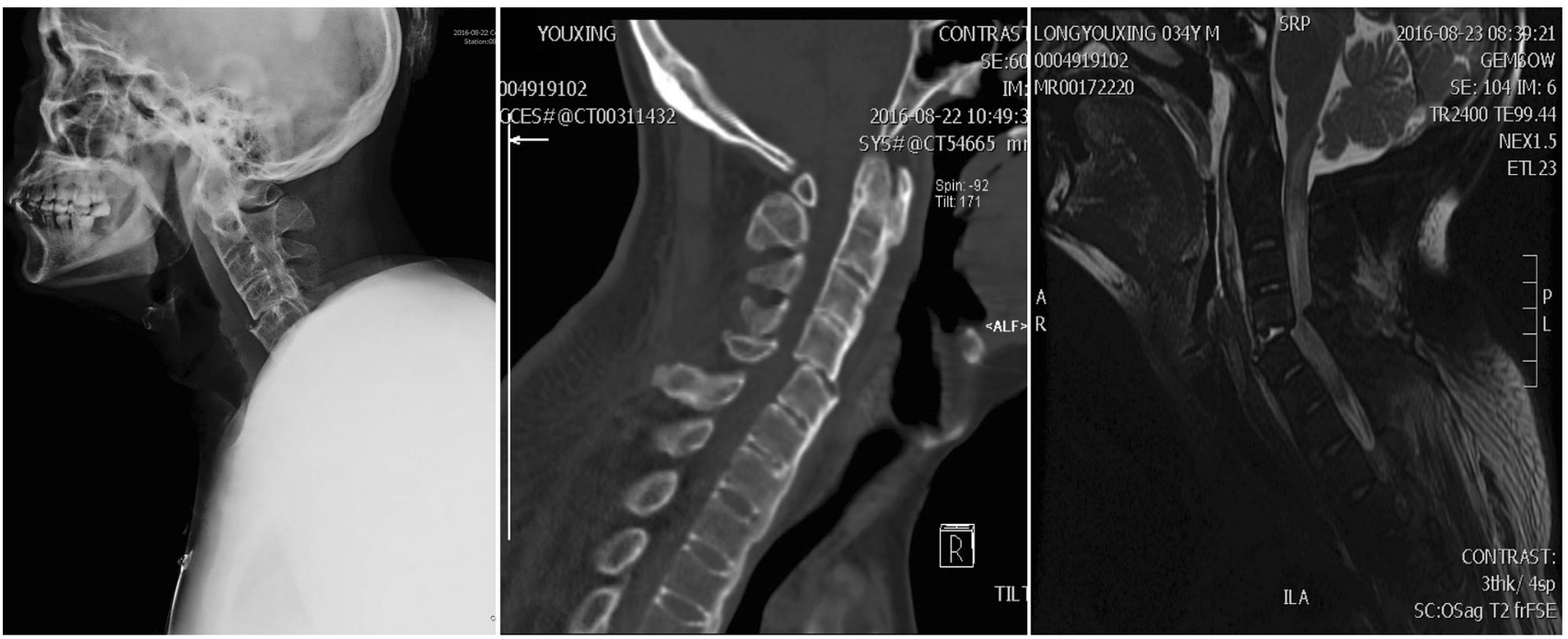

Fig. 1 Imaging of cervical spine showing bilateral fracture dislocation and angulation between C4 and C5 vertebrae involving both bony and ligamentous components

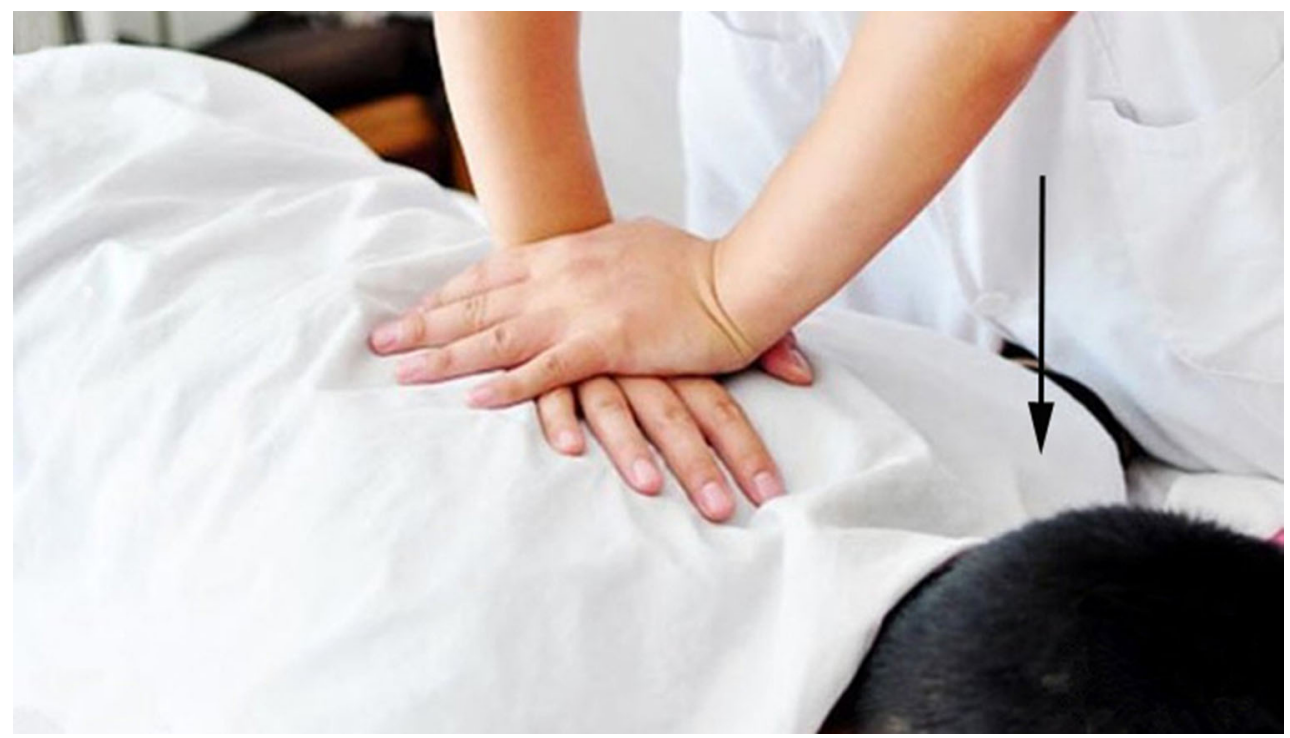

Fig. 2 Cervical tui-na manipulation sketch: the patient was placed in prone position, compressive force provided by the tui-na practitioner directly acted on the spinous processes

\section{Discussion}

Tui-na, being part of Traditional Chinese Medicine, is an ancient tradition, which is commonly used in China because of its success in treating specific musculoskeletal disorders (neck/back pain, sciatica, and arthritis) and chronic stress-related disorders of multiple systems. It involves various technical manipulations conducted by the practitioner's finger, hand, elbow, knee, or foot applied to muscle or soft tissue at specific body locations. Tui-na also incorporates many of the principles of acupuncture, including the use of acupoints. For example, tui-na often uses manual techniques such as pushing, rubbing, kneading, or high-intensity, high-frequency patting to clear energy blocks along specific meridians associated with particular conditions [5]. The infinite variations of tui-na application are derived from skilled use of the fundamental application of depth, pressure, drag, direction, speed, rhythm, frequency, and duration for variation in the quality of touch. All manipulations introduce mechanical forces into the soft tissues. These forces, which are set in the soft tissue, stimulate various physiologic responses [6]. The five kinds of force that can affect the tissues of the body are compression, tension, bending, shear, and torsion. Among 
them, compressive forces occur when two structures are pressed together; the force is applied perpendicularly. It is described as depth of pressure and is used therapeutically to affect circulation, sensory, and autonomic nerve stimulation, nerve chemicals, and connective tissue pliability. Therefore, it is alternatively used in combination with acupuncture and other manipulation techniques to treat AS in China [3, 4].

AS is seronegative autoimmune inflammatory arthritis that predominantly affects the spine and the sacroiliac joints [7]. The interaction between chronic inflammation and spine is primarily characterized by progressive ossification of the spinal ligaments and facet joints, which eventually leads to a fixed and stiff spine accompanying with vertebral osteoporosis [8, 9]. Therefore, with the development of AS, the ankylosed spine, most commonly in the cervical spine, is prone to fracture even once trivial trauma [10]. Thus, in general, compression above thoracic spine should be avoided and ankylosed joints should not be forcibly mobilized by tui-na in AS [11]. In our case, cervical hyperextension induced by compressive force vector (Fig. 2) produced bilateral fracture dislocation and wide angulation between $\mathrm{C} 4$ and $\mathrm{C} 5$ vertebrae involving both bony and ligamentous components.

Though tui-na is an alternative and effective method in treating patients with AS, the practitioner needs to be more cautious to tui-na manipulation choice. Compression above thoracic spine should be avoided in AS patients.

Author contribution statement All authors contributed to patient care and writing of the report. Written consent to publication was obtained.

\section{Compliance with ethical standards}

\section{Conflict of interest None.}

Funding National Natural Science Foundation of China (Project No. 81501651).
Open Access This article is distributed under the terms of the Creative Commons Attribution 4.0 International License (http://crea tivecommons.org/licenses/by/4.0/), which permits unrestricted use, distribution, and reproduction in any medium, provided you give appropriate credit to the original author(s) and the source, provide a link to the Creative Commons license, and indicate if changes were made.

\section{References}

1. Braun J, Sieper J (2007) Ankylosing spondylitis. Lancet 369:1379-1390

2. Klingberg E, Lorentzon M, Mellström D, Geijer M, Göthlin J, Hilme E, Hedberg M, Carlsten H, Forsblad-d'Elia H (2012) Osteoporosis in ankylosing spondylitis-prevalence, risk factors and methods of assessment. Arth Res Therapy 14:1

3. J-j Zhao (2015) Treatment of ankylosing spondylitis by fire-needle therapy plus tuina manipulations. J Acupunct Tuina Sci 13:15-21

4. Zhao Q, Graney CM, Xu B, Chen Y (2015) A case report of ankylosing spondylitis treated by acupuncture. Eur J BioMedical Res 1:18-22

5. Yang M, Feng Y, Pei H, Deng S, Wang M, Xiao X, Zheng H, Lai Z, Chen J, Li X, He X, Liang F (2014) Effectiveness of Chinese massage therapy (Tui Na) for chronic low back pain: study protocol for a randomized controlled trial. Trials 15:418. doi:10. $1186 / 1745-6215-15-418$

6. Hunt K (2010) Mosby's massage therapy review. Focus Alter Complem Therapies 15:338-339

7. El-Sharkawi MM, Koptan WM, El-Miligui YH, Said GZ (2011) Comparison between pedicle subtraction osteotomy and anterior corpectomy and plating for correcting post-traumatic kyphosis: a multicenter study. Eur Spine J 20:1434-1440

8. Debarge R, Demey G, Roussouly P (2011) Sagittal balance analysis after pedicle subtraction osteotomy in ankylosing spondylitis. Eur Spine J 20:619-625

9. Zhang HQ, Huang J, Guo CF, Liu SH, Tang MX (2014) Twolevel pedicle subtraction osteotomy for severe thoracolumbar kyphotic deformity in ankylosing spondylitis. Eur Spine J 23:234-241

10. Ghozlani I, Ghazi M, Nouijai A, Mounach A, Rezqi A, Achemlal L, Bezza A, El Maghraoui A (2009) Prevalence and risk factors of osteoporosis and vertebral fractures in patients with ankylosing spondylitis. Bone 44:772-776

11. Hymel GM, Rich GJ (2014) Health psychology as a context for massage therapy: A conceptual model with CAM as mediator. J Bodywork Move Therap 18:174-182 